\title{
Tarefas matemáticas para uma prova escrita: uma discussão a partir da produção escrita de alunos
}

\author{
RESUMO
}

Fernando Francisco Pereira fernandoutfcp@gmail.com 0000-0003-2082-5416 Universidade Tecnológica Federal do Paraná, Londrina, Paraná, Brasil.

\section{lara Souza Doneze}

iaradoneze@gmail.com

0000-0003-2766-5072

Universidade Tecnológica

Federal do Paraná, Londrina,

Paraná, Brasil.

\section{Marcele Tavares Mendes}

marceletavares1982@gmail.com

0000-0001-6844-6525

Universidade Tecnológica

Federal do Paraná, Londrina,

Paraná, Brasil.

\section{Jader Otavio Dalto}

jaderdalto@utfpr.edu.br

0000-0002-2918-3731

Universidade Tecnológica

Federal do Paraná, Londrina,

Paraná, Brasil.
Este artigo visa apresentar uma discussão a respeito do potencial de tarefas em uma prova escrita enquanto recursos para uma avaliação como prática de investigação em que, a partir da análise da produção escrita de alunos, o professor vai além da verificação de uma produção correta ou incorreta. Trata-se de uma pesquisa de natureza qualitativa de cunho interpretativo, ancorada em uma perspectiva de avaliação da aprendizagem como prática de investigação e oportunidade de aprendizagem. Os sujeitos da pesquisa foram 12 alunos matriculados no 6ㅇ ano do Ensino Fundamental, com idades entre 11 e 12 anos, em uma escola pública do Paraná, os quais realizaram uma prova escrita que contemplava operações básicas, com questões selecionadas do banco de questões da "Provinha Brasil". Essa discussão busca evidenciar características de tarefas avaliativas que potencializam o instrumento prova escrita para uma prática avaliativa em que o professor, a partir da análise da produção escrita, recolhe informações que subsidiam intervenções no processo de ensino e aprendizagem.

PALAVRAS-CHAVE: Educação matemática. Avaliação da aprendizagem. Prova escrita. Análise da produção escrita. 


\section{INTRODUÇÃO}

Ainda é comum, no contexto escolar, uma avaliação que serve para selecionar, classificar e rotular alunos, em que o professor decide se o aluno está apto ou não para seguir para a próxima turma/série/ano escolar, um sistema que deixa de lado o processo de aprendizagem para valorizar o resultado final, um produto que recebe uma certificação, uma classificação por meio de uma "nota". Tais práticas avaliativas servem a uma aprendizagem que busca avaliar a memorização e a reprodução do que foi "transmitido" pelo professor, não serve a uma aprendizagem enquanto um processo em construção e transformação.

Apesar de muitas questões sobre a avaliação da aprendizagem escolar já se encontrarem discutidas na literatura e apresentarem uma avaliação que subsidia os processos de ensino e de aprendizagem, ainda hoje, parece que um grande número de escolas estão restritas a uma prática avaliativa voltada a classificação e certificação dos alunos (HOFFMANN, 1991; BURIASCO,1999; ESTEBAN, 2001; BARLOW, 2006; LUCKESI, 2011; MORETTO, 2014). Esse contexto alimenta o interesse por novas investigações e estudos de práticas avaliativas comprometidas com a aprendizagem dos estudantes (BURIASCO et al. 2009; SANTOS, 2014).

Diante desse cenário, este trabalho se propõe, sob uma perspectiva de avaliação como prática de investigação, discutir, a partir da produção escrita dos alunos, o potencial das tarefas em uma prova escrita para repensar as práticas avaliativas, bem como seus contributos para as práticas pedagógicas, refletindo diretamente no ambiente de sala de aula.

Essa discussão utiliza apontamentos e caracterizações para tarefas feitas por Dekker e Querelle (2002), Moretto (2014) e Pereira Junior (2014), baseados em Van den Heuvel-Panhuizen (1996). Pretende-se, a partir da análise da produção escrita de alunos ao resolverem duas tarefas avaliativas de uma prova escrita, destacar potencialidades, limitações e possíveis adaptações ou reestruturações no enunciado, objetivando não só potencializar tais tarefas, mas também mostrar sua importância para uma reflexão e/ou intervenção no processo de ensino e de aprendizagem.

As tarefas que subsidiaram os dados dessa pesquisa, bem como as produções dos alunos, são de uma avaliação diagnóstica realizada em uma escola pública do estado do Paraná cujo objetivo foi investigar estratégias e procedimentos utilizados por alunos do 60 ano do Ensino Fundamental ao lidar com situações que demandam as quatro operações básicas. Os alunos, com idade entre 11 e 12 anos, faziam parte de uma turma do programa governamental "Novo mais Educação" ${ }^{1} \mathrm{e}$ tornaram-se sujeitos da pesquisa. Por limitação de espaço, foram selecionadas apenas duas tarefas para compor a discussão. Os critérios para a seleção das tarefas são apresentados nos procedimentos metodológicos.

Como ponto de partida, apresentam-se a prova escrita como instrumento de avaliação e as características de tarefas avaliativas nas duas seções subsequentes. Em seguida, destacam-se os aspectos dos procedimentos metodológicos considerados no desenvolvimento da pesquisa. Subsidiada pela construção teórica, apresenta-se uma discussão das produções dos alunos ao lidar com as duas tarefas selecionadas. Encerramos com as considerações finais, seguidas das referências bibliográficas. 


\section{O USO DA PROVA ESCRITA COMO INSTRUMENTO DE AVALIAÇÃO}

Hoffmann (1991) define avaliação como uma reflexão transformada em uma ação que impulsiona a novas reflexões do educador em toda a trajetória de construção do conhecimento realizada pelo educando, devendo ser um processo em que educador e educando aprendem. Barlow (2006, p. 15) coloca que a avaliação tem como "única finalidade o desenrolar da ação e torná-la mais condizente" e/ou ajustável à troca de informações.

Em sua tese, Buriasco (1999) destaca que avaliar é definir princípios a partir dos objetivos que se pretendem alcançar e escolher caminhos para essa ação. Destaca, ainda, que a Avaliação da Aprendizagem não possui uma finalidade, mas subsidia o decorrer de uma ação que vislumbra construir um resultado já definido previamente. Nessa perspectiva, o objetivo é a aprendizagem dos alunos e não a avaliação por si só. Com isso, em sala de aula, é desejável não valorizar somente o resultado final, é preciso que o professor considere o caminho que levou o aluno a tal resultado.

Ainda sobre avaliação, Esteban (2001, p. 22) traz que "avaliar é interrogar e interrogar-se", reconhecendo a avaliação como prática de investigação, a qual dá visibilidade e "abre espaço para [...] o múltiplo e o desconhecido":

\footnotetext{
As respostas predeterminadas cedem lugar às respostas em constante construção, desconstrução e reconstrução, que passam a configurar o início de novos questionamentos (ESTEBAN, 2001, p. 22 - 23).
}

Esse novo olhar para a avaliação, liberto do ato de classificar, possibilita que o professor conceba os caminhos percorridos pelos alunos, as estratégias e os procedimentos adotados por eles buscando solucionar tarefas, assim como suas principais dificuldades, erros e aquilo que estão próximos de saber, oportunizando, assim, uma tomada de decisão pelo professor. Desse modo, cabe ressalvar que, diante dessa perspectiva de avaliar sob uma prática investigativa, as tarefas propostas devem servir para "pensar, refletir, criticar, levantar hipóteses, compreender e correlacionar conteúdos" (BURIASCO et al., 2009, p. 76).

Ao tratar do tema avaliação, muitas pessoas relatam situações baseadas em suas próprias experiências, de quando elas foram submetidas a alguma situação avaliativa. Entre esses relatos, poucos são aqueles que deixam de citar experiências com a prova escrita. Há tempos, a prova escrita é vista como principal, senão único, instrumento utilizado no ambiente escolar como forma de avaliar os alunos (BURIASCO et al., 2009; PEREGO 2009; MORETTO, 2014).

Ao falar em prova escrita no sentido sistêmico, anteriormente discutido, Trevisan e Mendes (2015) classificam-na como uma proposta a ser resolvida individualmente, sem consulta a nenhum tipo de material de apoio e com tempo limitado. Embora haja uma predileção dos professores em utilizar a prova escrita, é preciso destacar a prática de apenas apontar o erro dos alunos e não o que eles demonstram saber, utilizando o instrumento a partir de uma correção pela falta (VAN DEN HEUVEL-PANHUIZEN, 1996; CELESTE, 2008; BURIASCO et al., 2009).

Diante desses apontamentos, não se espera a abolição da prova escrita, mas possíveis ressignificações, de modo que se potencialize a prova escrita (VAN DEN HEUVEL-PANHUIZEN, 1996, p. 134). Para Buriasco et al. (2009, p. 78), o equívoco não é olhar para a prova escrita apenas como instrumento de avaliação, mas deixar 
de vê-la "como um meio pelo qual se podem obter informações a respeito de como se tem desenvolvido o processo de aprendizagem dos estudantes". Na visão de Trevisan e Mendes (2015, p. 54), há que fazer uma "ressignificação" da prova escrita, "no sentido de compreender a avaliação enquanto oportunidade de aprendizagem tanto para o estudante quanto para o próprio professor".

Nesse processo de conceber e empregar a avaliação como oportunidade de aprendizagem, a prova escrita passa a ser um instrumento de avaliação que serve a uma prática de investigação e coleta de dados, no qual estão impressas as representações e concepções dos alunos, em outras palavras, sua produção escrita, "ampliando assim a capacidade do professor em observar, constatar e descrever a realidade da aprendizagem" de seus alunos (LUCKESI, 2011, p.304). Ao professor é dada a oportunidade de recolher informações acerca do que acontece na sala de aula, conhecer as estratégias e os procedimentos que os alunos utilizam, quais dificuldades apresentam, quais são seus erros, o que sabem e o que estão próximos de saber (PEREGO, 2006; DALTO, 2007; CELESTE, 2008).

Com o propósito de olhar para a produção escrita dos alunos em provas escritas, cabe atentar para a organização e a elaboração das tarefas de avaliação, de modo a potencializar a prova escrita. As tarefas devem encorajar os alunos a uma reflexão e a revelar o processo de solução feito por eles (VAN DEN HEUVELPANHUIZEN, 1996). Assim, conforme Luckesi (2011, p. 360), deve-se fazer uma seleção adequada de tarefas que "desafiem" o estudante a "manifestar sua aprendizagem em termos de informações, habilidades e condutas".

\section{TAREFAS DE AVALIAÇÃO PARA UMA PROVA ESCRITA: UMA REFLEXÃO NECESSÁRIA}

Em uma prática avaliativa tradicional, os professores selecionam as tarefas avaliativas que julgam adequadas, segundo seus próprios critérios, baseando-se em seus objetivos e interpretações, enquanto "a preocupação dos alunos é satisfazer os professores, é tentar responder tudo o que o professor quer para, com isso, obter a nota" (MORETTE, 2014, p. 117).

Entretanto, caberia ao professor intervir, planejar tarefas com um olhar revelador, "ir além", atento ao potencial de gerar informações para a ação educativa do professor em uma prática avaliativa investigativa, a serviço da aprendizagem dos estudantes (HOFFMANN, 1991; DALTO, 2007; BURIASCO et al., 2009; MENDES, 2014). Nesse processo, a preocupação do aluno é alterada, pois ele passa a preocupar-se com sua aprendizagem, reconhecendo-se sujeito ativo do processo de aprender.

Ao olhar para possíveis tarefas que irão compor uma avaliação, os professores, segundo Dekker e Querelle (2002), podem analisá-las segundo alguns critérios: tópico. 
- Esta exigirá habilidades de leitura, o que acredito que muitos dos meus alunos não tenham.

- Esta é realmente difícil porque os alunos precisam escrever argumentos matemáticos.

- $\quad$ Esta, a maioria dos meus alunos não será capaz de fazer, porque eles realmente precisam integrar diferentes conteúdos matemáticos e ser criativos ao encontrar seu próprio caminho para solucionar o problema (DEKKER; QUERELLE, 2002).

Com esses critérios, na maioria das vezes, os professores podem estar certos, porém, em algum momento, também podem ser surpreendidos pelos alunos (DEKKER; QUERELLE, 2002), o que só poderá ocorrer se aceitarem olhar para além dos "erros" e "acertos". Hofmann (1991, p. 62) é concludente ao afirmar:

\begin{abstract}
se valorizamos os "erros" dos alunos, considerando-os essenciais para o "vir a ser" do processo educativo, temos de assumir também a possibilidade das incertezas, das dúvidas, dos questionamentos que possam ocorrer conosco a partir da análise das respostas deles, favorecendo, então, a discussão sobre essas ideias novas ou diferentes (HOFFAMANN, 2001, p. 62, grifo dos autores).
\end{abstract}

Diante das incertezas, dúvidas e novas ideias que podem surgir, Morette (2014, p. 123) atenta para as formas de elaboração das tarefas de avaliação:

Em primeiro lugar [...] se a pergunta não é clara e precisa, ela permite muitas respostas, todas corretas, embora diferentes das esperadas por quem perguntou. Em segundo lugar, é certo que o contexto dá sentido ao texto; assim alguém poderia argumentar que uma resposta numa prova deve ser dada em função do contexto do ensino, isto é, de acordo com o que o professor apresentou em aula (MORETTE, 2014, p. 123).

Para buscar satisfazer os apontamentos apresentados anteriormente, é desejável que os professores recorram a tarefas em diferentes níveis de competência. Ademais, o conteúdo matemático envolvido nas tarefas e a sua complexidade devem ser levados em consideração (DEKKER; QUERELLE, 2002).

No que concerne à elaboração de tarefas de avaliação, Pereira Junior (2014), embasado em Van den Heuvel-Panhuizen (1996), apresenta características de bons problemas de avaliação (Quadro 1).

Quadro 1 - Características de bons problemas de avaliação segundo Pereira Junior (2014).

Informativos: expressar o máximo de informações possível a respeito do conhecimento dos alunos e de como aplicam esse conhecimento em situações novas e revelar algo do processo subjacente às escolhas das estratégias e procedimentos feitos pelo aluno

Significativos: ser atraente, convidativo, desafiador e interessante matematicamente; não se caracterizar como questão rotineira, possibilitando ser abordado de diferentes maneiras e em diferentes níveis de compreensão.

Transparentes: permitir que os alunos mostrem o nível em que eles se encontram; possibilitar informações para que todos os alunos resolvam ou pelo menos tentem solucioná-lo. 
Elásticos/Flexíveis: exigir mais que reproduzir algo decorado; possibilitar que os alunos mostrem seus potenciais e poder ser resolvido por diferentes estratégias, em diferentes níveis de aprendizagem, utilizando, muitas vezes, suas experiências pessoais na elaboração de suas próprias respostas; oportunizar que professor e aluno aprendam a partir da resolução e da resposta à tarefa.

Acessíveis: ter enunciado claro, que evidencie se o conhecimento envolvido é insuficiente para a solução, e proporcionar oportunidades para o aprofundamento.

(Fonte: Os autores baseado em Pereira Junior (2014).)

Uma prova escrita por si mesma não possibilita as respostas necessárias para gerir e compreender os processos de ensino e de aprendizagem, mas favorece um construto: a produção escrita de cada aluno. $E$ as informações, recolhidas a partir de uma produção escrita, melhores serão quanto mais flexibilidade o problema tiver para que os alunos demonstrem o que sabem, para matematizar e ser resolvido de formas diferentes, o que permite ao aluno mostrar em que nível se encontra (MENDES, 2014).

\section{PROCEDIMENTOS METODOLÓGICOS}

Os aspectos metodológicos aqui apresentados servem a uma pesquisa qualitativa de cunho interpretativo, que evidenciou a análise da produção escrita de alunos em tarefas de uma prova escrita como um caminho profícuo para repensar o contexto avaliativo escolar. O contexto evidenciado é reconhecido como aquele que está a serviço das práticas pedagógicas, na direção de guiar e fomentar as intervenções do professor, assim como a necessidade de refletir sobre o potencial de cada tarefa de uma prova escrita.

Como uma possibilidade de tratamento dos dados, analisar a produção escrita fornecida pelos alunos possibilita ao professor investigar o processo de ensino e de aprendizagem como um todo. Munido das informações, o professor tem a possibilidade de investigar o que acontece na sala de aula, as estratégias utilizadas pelos alunos, os erros cometidos por eles. Além disso, a análise da produção escrita dos alunos subsidia a elaboração de intervenções em sala de aula num contexto geral (DALTO, 2007; CELESTE, 2008; SANTOS, 2014).

\section{O CENÁRIO E OS SUJEITOS DA PESQUISA}

As tarefas apresentadas, bem como as produções dos alunos, constituem parte de uma avaliação diagnóstica feita pela professora e autora deste trabalho em uma escola pública do estado do Paraná com 12 alunos do 60 ano do Ensino Fundamental, objetivando colher informações do modo de lidar dos alunos com situações que demandem a utilização das quatro operações básicas. Os particantes, com idade entre 11 e 12 anos, faziam parte de uma turma do programa governamental "Novo mais Educação", programa público que visa à promoção da educação integral no Brasil.

O instrumento de diagnóstico, inicialmente composto de 5 itens de múltipla escolha, foi adaptado por se considerar que questões de múltipla escolha não revelam muitas informações de como os alunos chegaram à resposta, pois 
permitem que os alunos respondam corretamente a partir de cálculos errados, além de trazerem o sentido de que os problemas matemáticos sempre possuem respostas e que estas são sempre únicas (VAN DEN HEUVEL-PANHUIZEN, 1996; DEKKER; QUERELLE, 2002).

Por uma limitação de espaço, destacam-se neste trabalho apenas duas tarefas, as quais foram julgadas propícias ante os objetivos. Os critérios empregados na seleção das tarefas e das produções que vieram a embasar a análise deram-se a partir de uma dinâmica reflexiva desenvolvida pelos autores em uma disciplina intitulada "Avaliação da Aprendizagem e Ensino de Matemática" no âmbito do Mestrado Profissional em Ensino de Matemática - PPGMAT da Universidade Tecnólogica Federal do Paraná - UTFPR. A dinâmica dispôs aos professores-mestrandos do PPGMAT todas as tarefas, assim como as produções escritas dos alunos para que eles julgassem, avaliassem e refletissem acerca das potencialidades e limitações por trás de cada produção. Portanto, as tarefas selecionadas para análise nessa pesquisa foram justamente as que mais despertaram a discussão e a reflexão dos professores-mestrandos.

No Quadro 2, estão os enunciados e possíveis resoluções para duas tarefas da prova, que serão analisadas e discutidas na próxima seção.

Quadro 2 - Enunciado da Tarefa 1 e Resoluções feitas pelos autores considerando estratégias distintas e em diferentes níveis de compreensão.

\begin{tabular}{|c|c|c|c|c|c|c|c|}
\hline \multicolumn{8}{|c|}{$\begin{array}{l}\text { Num pacote de balas contendo } 10 \text { unidades, o peso líquido é de } 49 \text { gramas. Em } 5 \\
\text { pacotes, teremos quantos gramas? }\end{array}$} \\
\hline \multicolumn{4}{|c|}{$\begin{array}{l}\text { Estratégia utilizando a informação } \\
\text { extra, "contendo } 10 \text { unidades". }\end{array}$} & \multicolumn{4}{|c|}{$\begin{array}{l}\text { Estratégia utilizando apenas a multiplicação e } \\
\text { ignorando a informação extra. }\end{array}$} \\
\hline \multicolumn{4}{|c|}{$\begin{array}{l}10 \text { unidades e } 49 \text { gramas. } \\
\frac{49}{10} \text {, teremos que cada unidade tem } \\
\text { aproximadamente } 4,9 \mathrm{~g} \text {. } \\
\text { Logo, em } 5 \text { pacotes contendo } 10 \\
\text { balas, teremos } 5 * 10=50 \text { balas, } \\
\text { como cada bala possui } \\
\text { aproximadamente } 4,9 \mathrm{~g} \text {, então } 5 \\
\text { pacotes terão, } 4,9 * 50=245 \mathrm{~g} \text {. }\end{array}$} & \multicolumn{4}{|c|}{$\begin{array}{l}49 \text { gramas cada pacote, então, em } 5 \text { pacotes } \\
\text { teremos: } \\
49 * 5=245 \mathrm{~g}\end{array}$} \\
\hline \multicolumn{8}{|c|}{$\begin{array}{l}\text { Uma escola recebeu a doação de } 3 \text { caixas de } 1000 \text { livros, mais } 8 \text { caixas de } 100 \text { livros, } \\
\text { mais } 5 \text { pacotes de } 10 \text { livros, mais } 9 \text { livros. Quantos livros essa escola recebeu? }\end{array}$} \\
\hline \multicolumn{4}{|c|}{$\begin{array}{l}\text { Estratégia utilizando apenas a } \\
\text { adição }\end{array}$} & \multicolumn{4}{|c|}{ Estratégia utilizando a multiplicação e a adição. } \\
\hline 1000 & 100 & 10 & 3000 & & & & \\
\hline 1000 & 100 & 10 & 800 & 1000 & 100 & 10 & 3000 \\
\hline+1000 & 100 & 10 & 50 & $\underline{\times} \quad 3$ & $\underline{\times 8}$ & $\underline{\times 5}$ & 800 \\
\hline \multirow[t]{6}{*}{3000} & 100 & 10 & $\begin{array}{r}9 \\
+\quad 9 \\
\end{array}$ & 3000 & 800 & 50 & 50 \\
\hline & 100 & +10 & $\overline{3859}$ & & & & +9 \\
\hline & 100 & & & & & & 3859 \\
\hline & 100 & & & & & & \\
\hline & 100 & & & & & & \\
\hline & 800 & & & & & & \\
\hline \multicolumn{4}{|c|}{ A escola recebeu 3859 livros. } & \multicolumn{4}{|c|}{ A escola recebeu 3859 livros. } \\
\hline
\end{tabular}

(Fonte: Os autores.) 
As tarefas apresentadas foram selecionada, pois acredita-se que são propícias a uma discussão a partir das possíveis soluções feitas pelos alunos. Na Tarefa 1, ao considerar a expressão "contendo 10 unidades" como uma informação extra, atenta-se para sua irrelevância na resolução da tarefa, o que pode causar equívocos na resolução da tarefa.

\section{UMA DISCUSSÃO}

A partir das características de "bons" problemas para avaliação, apresentadas no Quadro 1, procurou-se classificar as tarefas, bem como justificar tal classificação. As classificações e justificativas são apresentadas no Quadro 3 e no Quadro 4, respectivamente.

Quadro 3 - Características de "bons" problemas para avaliação" na Tarefa 1

Num pacote de balas contendo 10 unidades, o peso líquido é de 49 gramas. Em 5 pacotes teremos quantos gramas?

Informativos

O problema traz um contexto familiar para o aluno, convidativo, e oferece a oportunidade de abordar e mostrar competências com relação à multiplicação. Ao lidar com a tarefa, o aluno tem a oportunidade de desenvolver estratégias e procedimentos relacionados à multiplicação. As informações do enunciado favorecem que todos, pelo menos, tentem solucioná-los.

A tarefa em si já permite que o aluno resolva utilizando estratégias envolvendo tanto adição quanto multiplicação, isto é, é possível

Significativos resolvê-la por meio de mais de uma estratégia, o que a torna mais acessível. Ainda, atrelando-se a informação extra já descrita, permite que os alunos mostrem seu potencial matemático, portanto

Elásticos/flexíveis possibilita ser abordada de diferentes maneiras e níveis de compreensão. Assim, "não só os alunos mais avançados podem resolver, mas os alunos com mais dificuldade também podem, em um nível mais baixo", Van Den Heuvel-Panhuizen (1996, p. 94).

(Fonte: Os autores.)

A Tarefa 1 apresentou subsídios que permitiram colocá-la dentro de todas as características de bons problemas apresentadas no Quadro 1.

Do mesmo modo, o Quadro 4 apresenta uma classificação e justificativa da Tarefa 2.

Quadro 4 - Características de “bons” problemas para avaliação” na Tarefa 2

Uma escola recebeu a doação de 3 caixas de 1000 livros, mais 8 caixas de 100 livros, mais 5 pacotes de 10 livros, mais 9 livros. Quantos livros essa escola recebeu?

Informativos $\quad$ Apesar de o contexto não fazer parte de atividades diretas dos alunos, é possível ser imaginado pelos alunos. A tarefa pode ser resolvida a 


\begin{tabular}{|c|l|}
\hline Acessíveis & $\begin{array}{l}\text { partir de estratégias envolvendo tanto adição quanto multiplicação, } \\
\text { favorecendo a flexibilidade da resolução. Isso também faz com que a } \\
\text { tarefa seja acessível aos alunos, podendo ser abordada de diferentes } \\
\text { maneiras e em diferentes níveis de compreensão (devido às } \\
\text { estratégias descritas e considerando que muitos alunos dos anos } \\
\text { iniciais do Ensino Fundamental ainda não concebem a multiplicação } \\
\text { como a adição de fatores iguais). Pode ser considerada transparente } \\
\text { pransparentes permitir que todos os alunos sejam capazes, de certa forma, de } \\
\text { resolver ou de pelo menos tentar resolvê-la. Acredita-se que o } \\
\text { enunciado expressa claramente o que foi requisitado, além de } \\
\text { evidenciar previamente quais estratégias podem ser tomadas. Esse } \\
\text { fato pode ser notado no uso de palavras como "mais" e na forma } \\
\text { como os dados vão sendo apresentados (de modo que, ao serem } \\
\text { calculados na ordem de apresentação, os alunos obterão os } \\
\text { resultados do maior para o menor valor, facilitando sua disposição na } \\
\text { hora de usar a estratégia de "armar" a adição, estratégia comumente } \\
\text { utilizada por professores dos anos iniciais do Ensino Fundamental ao } \\
\text { ensinar adição). }\end{array}$ \\
\hline Elásticos/flexíveis
\end{tabular}

(Fonte: Os autores.)

Serão apresentadas algumas produções escritas, intecionalmente selecionadas. Por meio delas, espera-se promover uma discussão com o intuito de destacar o potencial dessas tarefas reconhecido teoricamente, bem como uma adaptação e/ou aprimoramento.

A Figura 1 apresenta uma produção escrita realizada por um dos alunos, denominado $\mathrm{A} 2$, ao resolver a Tarefa 1.

Figura 1 - Produção escrita de A2 ao resolver a Tarefa 1

1) Num pacote de balas contendo 10 unidades, o peso liquido é de 49 gramas. Em 5 pacotes teremos quantos gramas?

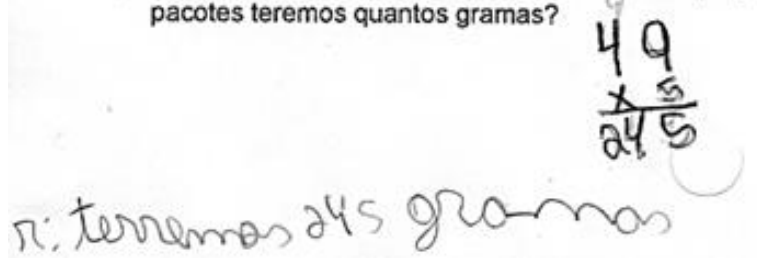

(Fonte: Arquivo dos autores.)

Pode-se inferir que esse aluno interpretou a situação, utilizou corretamente a operação de multiplicação como estratégia de solução, não utilizou a informação extra (cada pacote tem 10 unidades) e respondeu corretamente à tarefa. Encaminhamento diferente é dado pelo aluno A1, ao resolver a Tarefa 1 como apresentado na Figura 2.

Figura 2 - Produção escrita de A2 ao resolver a Tarefa 1

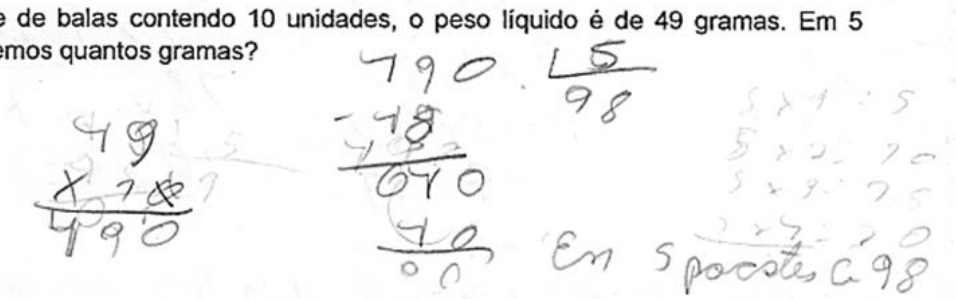

(Fonte: Arquivo dos autores.) 
Ao analisar a produção de A1 (Figura 2), nota-se que ele utilizou as operações de multiplicação e de divisão. Os procedimentos de multiplicação e de divisão foram corretamente efetuados apesar de não resolverem o problema. Conforme Buriasco et al. (2009), a produção do aluno deve fazer o professor interrogar-se e refletir. Esse aluno, apesar de ter escolhido uma estratégia incorreta, revela saber realizar operações de multiplicação e divisão. Seria, então, uma tarefa em que o aluno deve obter nota zero, se o objetivo era observar também como ele lida com as operações básicas?

Para essas pesquisadoras, diferentemente de uma perspectiva de avaliação que procura reduzir os processos às respostas encontradas, o foco da avaliação como prática de investigação "está em interrogar os meios, as trajetórias, os caminhos percorridos que as originaram" (BURIASCO et al. 2009, p. 76). Essa prática rompe com a dicotomia de certo e errado, com resultados exatos e precisos de alunos ao resolver tarefas matemáticas.

Nessa tarefa seria possível e desejável que o professor pedisse que o aluno A1 a resolvesse a partir da retirada da informação extra. As tarefas de avaliação devem servir para intervir nos processos de aprendizagem. Após resolver sem o dado extra, o professor pode pedir que o aluno leia os dois enunciados e perceba as diferenças. Com essa ação, o professor transforma uma tarefa de prova em uma ferramenta de ensino, o que lhe permite acompanhar o processo individual de aprendizagem de seus estudantes.

A Figura 3 apresenta a produção do aluno A1 acerca da segunda tarefa.

Figura 3 - Produção escrita de A1 ao resolver a Tarefa 2

3) Uma escola recebeu a doação de 3 caixas de 1000 livros, mais 8 caixas de 100 livros, mais 5 pacotes de 10 livros, mais 9 livros. Quantos Livros essa Escola recebeuz

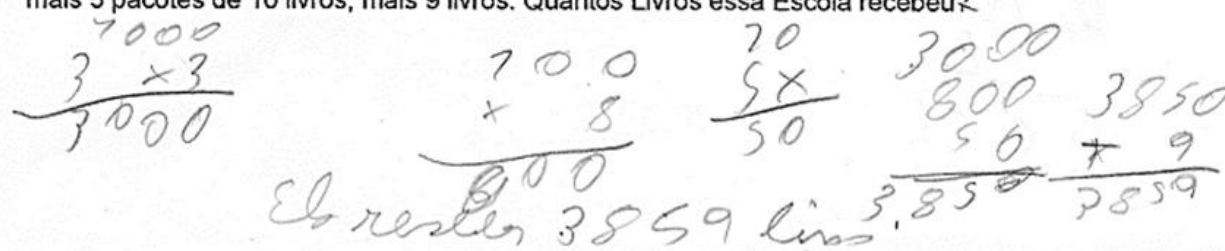

(Fonte: Arquivo dos autores.)

Em sua produção escrita, A1 utiliza a multiplicação como estratégia de resolução. Posteriormente, faz a adição das parcelas resultantes das multiplicações para depois encontrar a resposta do problema a partir de uma segunda adição. Esta última envolve o resultado obtido anteriormente adicionado ao valor no qual a multiplicação não estava envolvida ("mais 9 livros"). Isso mostra uma das características de problema elástico/flexível (Quadro 1), que é poder ser resolvido por diferentes estratégias e despertar o potencial matemático dos alunos.

Ressalta-se que essa produção (Figura 3) é do mesmo aluno que não interpretou corretamente as informações do enunciado da Tarefa 1. Para além de verificar se a produção está correta ou incorreta, o professor que analisa a produção escrita tem a oportunidade de observar que esse aluno possui a habilidade de resolver problemas matemáticos e de realizar operações básicas. Tarefa 2. 
Figura 4 - Produção escrita de A2 ao resolver a Tarefa 2

3) Uma escola recebeu a doação de 3 caixas de 1000 livros, mais 8 caixas de 100 livros, mais 5 pacotes de 10 livros, mais 9 livros. Quantos Livros essa Escola recebeu?

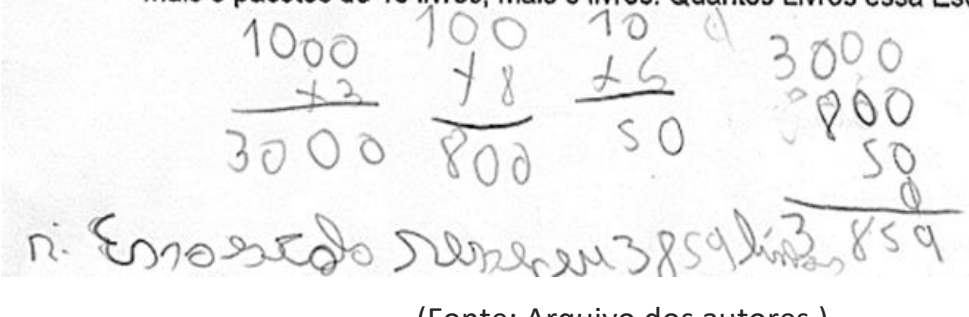

(Fonte: Arquivo dos autores.)

Por meio da produção escrita apresentada na Figura 4, pode-se observar que A2, assim como A1 (Figura 3), também faz uso da multiplicação como estratégia inicial e, posteriormente, da adição, porém de um jeito mais sucinto e convencional. Vale ressaltar que, se necessário, a tarefa em questão possibilitava ter como única estratégia de resolução a adição. De fato, alguns alunos fizeram uso dessa estratégia como se pode perceber na produção do aluno A3 apresentada na Figura 5.

Figura 5 - Produção escrita de A1 ao resolver a Tarefa 2

3) Uma escola recebeu a doação de 3 caixas de 1000 livros, mais 8 caixas de 100 livros, mais 5 pacotes de 10 livros, mais 9 livros. Quantos Livros essa Escola recebeu?

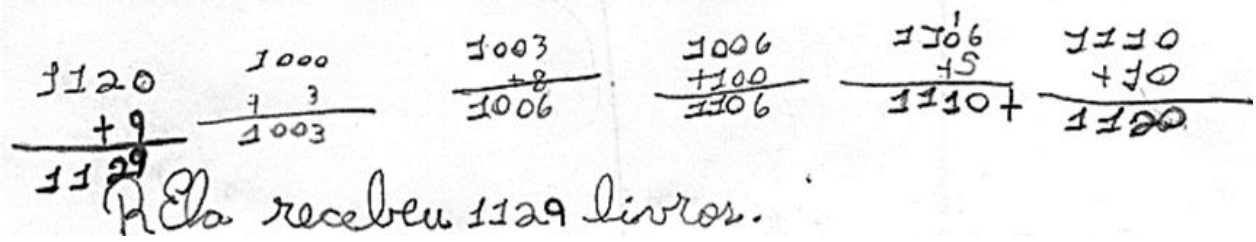

(Fonte: Arquivo dos autores.)

Utilizar somente a adição como estratégia de resolução era possível e esperado, porém esse aluno não reconhece que os números 3,8 e 5 são os números de caixas de 1000, 100 e 10 livros, respectivamente. Neste caso, a estratégia de adicionar os valores em cada uma das hipóteses do problema não o resolveu. Além disso, é possível reconhecer que o aluno possui dificuldades em efetuar corretamente a operação escolhida para lidar coma tarefa. A partir dessa produção, o professor pode trabalhar adição de parcelas iguais como o conceito de multiplicação. Uma sugestão é o professor utilizar o material dourado ou outros materiais manipuláveis como o Ábaco. Essas alternativas auxiliariam na retomada da operação de adição e reconhecimento das unidades, dezenas, centenas visando ajudar o aluno a resolver adições, por exemplo, das parcelas 1003 e 8 apresentadas na produção. Essa prática favorece que o professor utilize as informações recolhidas em uma produção escrita para subsidiar intervenções pedagógicas na direção de oportunizar ao aluno novos momentos de reflexão e aprendizagem a partir de uma tarefa de avaliação.

Como já mencionado, a Tarefa 2 permite ser abordada de diferentes maneiras e em diferentes níveis de compreensão, visto que não exige uma única estratégia. Um fato que não pode ser afirmado, tendo como base somente a interpretação da produção apresentada, é o quão a palavra "mais", repetida algumas vezes na Dekker e Querelle (2002) já haviam atentado diante da situação de analisar 
possíveis tarefas para compor uma prova escrita, indagar: "Esta exigirá habilidades de leitura, o que acredito que muitos dos meus alunos não tenham"? Assim, para Dekker e Querelle (2002), um cuidado maior deve ser dado à linguagem usada nas provas. Como auxílio para esses casos, ambos afirmam que o professor deve tomar a prova e ler as tarefas com os alunos em voz alta, descrevendo o conteúdo da tarefa com diferentes palavras, mesmo que isso afete a complexidade da tarefa.

Diante do cenário anterior, julga-se necessário, em alguns casos, como a apresentação da informação extra na Tarefa 1 , uma reestruturação da tarefa a fim de que todo seu potencial para o ensino e aprendizagem possa ser atingido. Conforme Mendes (2014), mais do que "boas" questões, é preciso que o professor reflita acerca dos meios de flexibilizá-las para que os alunos apresentem seu poder matemático.

\section{CONSIDERAÇÕES FINAIS}

De início, vale considerar que as tarefas citadas foram realizadas com doze alunos e que todas as produções foram discutidas, refletidas e analisadas, porém, devido à limitação de espaço, o texto restringiu-se a apresentar algumas produções de duas tarefas. Tem-se, de uma forma geral, que, na Tarefa 1, o enunciado traz informações extras. Esse fato proporciona uma oportunidade a mais para o professor observar o modo como o aluno lida com as informações do enunciado da tarefa, possibilitando outros caminhos para a solução e o contato com novos conceitos e novos conteúdos. Nesse sentido, ao tecermos considerações acerca da análise das produções escritas dos alunos na Tarefa 1, pode-se perceber que essa informação influenciou a interpretação e, consequentemente, a solução da tarefa. A escolha dessa tarefa foi proposital, como forma de se atentar a como os alunos lidam com tais informações extras. É preciso destacar, porém, que situações assim devem ser previamente analisadas, para então compor uma tarefa de avaliação. Conforme Van den Heuvel-Panhuizen (1996), não é possível tratar separadamente as tarefas de avaliação dos problemas de gestão didática, eles precisam ter relação e coerência entre eles.

No que se refere à Tarefa 2, o enunciado passou a confundi-los ao apresentar diversas vezes a palavra "mais". Isso, provavelmente, possibilitou que os alunos fizessem associações com uma das operações básicas, a adição, o que de fato aconteceu. $\mathrm{O}$ contexto no qual os alunos a interpretam não condiz com o que a tarefa requisita, como fica explícito na solução da Tarefa 2 feita por A3 (Figura 5). Nesse caso, embora a tarefa também pudesse ser resolvida apenas por meio da adição, sua estratégia foi adicionar todos os valores que apareceram no enunciado.

Diante dos fatos apresentados, é nítida a preocupação que o professor deve ter ao selecionar questões para compor suas tarefas de avaliação, pois o simples acréscimo de uma palavra em uma frase, ou um dado extra, pode fazer o aluno transitar entre não fazer uso de uma estratégia adequada e deixar de revelar seus conhecimentos. Conforme Buriasco et al. (2009), o professor pode nortear uma análise da produção escrita a partir de algumas questões, que também podem ser usadas no momento da escolha da tarefa: As dificuldades de interpretação estão relacionadas à linguagem utilizada no enunciado, ao conteúdo envolvido, a ambos, ou a outros aspectos? As informações presentes no enunciado da tarefa fazem parte do conjunto de circunstâncias que tornam a tarefa acessível aos estudantes? 
É preciso que o professor atente para a reestruturação das tarefas a fim de chegar às indagações que permitirão aos alunos irem além do esperado. Ao elaborar/selecionar tarefas, o professor deve levar em consideração as características do ambiente escolar, do qual os alunos fazem parte, e as práticas de ensino e aprendizagem. Isso só é possível quando se adota uma prática investigativa que ultrapassa o âmbito da avaliação da aprendizagem.

Por fim, frente a todo o exposto e discutido acerca de conceber a avaliação como um "ir além" da prática de valorar e classificar, atentando para as produções escritas dos alunos como uma perspectiva de investigar e repensar todas as ações que permeiam o ambiente de sala de aula, considera-se atingido o objetivo deste trabalho que era discutir as possibilidades de potencializar as tarefas não só para a aprendizagem dos alunos, mas também para a ação docente e todo o processo de ensino. Nesse sentido, espera-se que este trabalho contribua para a formação docente e seja um acréscimo ao campo das pesquisas que tiveram como foco as tarefas de avaliação e a aprendizagem de Matemática. 


\title{
Assessment tasks for a written test: an analysis from student's written production
}

\begin{abstract}
This paper aims to present a discussion about the potential of tasks in a written test as resources for an assessment as an investigation practice in which, from the analysis of written production of students, the teacher goes beyond checking for a correct production or incorrect. It is a qualitative research of an interpretive nature, anchored in a perspective of assessment of learning as investigation practice and learning opportunity. The subjects of the research were 12 students enrolled in the 6th year of primary education, aged 11 to 12 years, in a public school in the state of Paraná, Brazil. The students performed a written test in which the basic content was the basic operations. This discussion aims to report characteristics of assessment tasks that potentiate the writing test, performing an assessment practice in which the teacher uses the analysis of written production as an opportunity to gather information to carry out interventions in the teaching and learning process.
\end{abstract}

KEYWORDS: Mathematics education. Learning assessment. Written test. Written production analysis. 


\section{NOTAS}

1 Novo mais Educação é um programa do Ministério da Educação que tem como objetivo melhorar a aprendizagem em língua portuguesa e matemática no ensino fundamental, por meio da ampliação da jornada escolar de crianças e adolescentes. Mais informações em: https://goo.gl/ix9wNM

\section{REFERÊNCIAS}

BARLOW, M. Avaliação escolar - mitos e realidades. Porto Alegre: Artmed, 2006.

BURIASCO, R. L. C. de et al. Avaliação como Prática de Investigação (alguns apontamentos). BOLEMA, v. 33, p. 69-96, 2009. Disponível em:

<https://goo.gl/SHpjKq> Acesso em: 24 out. 2017

BURIASCO, R. L. C. Avaliação em Matemática: um estudo das respostas dos alunos e professores. 1999. 238 f. Tese de Doutorado. Universidade Estadual Paulista, Marília, 1999.

CELESTE, L. B. A Produção escrita de alunos do Ensino Fundamental em questões de matemática do PISA. 2008. 85f. Dissertação de Mestrado (Programa de Pós-Graduação em Ensino de Ciências e Educação Matemática) Universidade Estadual de Londrina, Londrina. 2008.

DALTO, J. O. A produção escrita em matemática: análise interpretativa da questão discursiva de matemática comum à 8 a série do Ensino Fundamental e a 3a série do Ensino Médio da AVA/2002. 2007. 100f. Dissertação de Mestrado (Programa de Pós-Graduação em Ensino de Ciências e Educação Matemática) Universidade Estadual de Londrina, Londrina. 2007.

DEKKER, T.; QUERELLE, N. Great Assessment Problems. Utrecht: Freudenthal Institute, 2002. Disponível em: <https://goo.gl/F3r9WD> Acesso em: 26 de nov. 2017.

DEKKER, T.; QUERELLE, N. Grandes Problemas de la Evaluación. Utrecht. Freudenthal Institute. Trad. GALLEGO, F. Bariloche, Río Negro: GPDM, Argentina, 2002. Disponível em: <https://goo.gl/5Qz73w> Acesso em: 26 de nov. 2017.

ESTEBAN, M. T. (org.) Avaliação: uma prática em busca de novos sentidos. Rio de Janeiro: DP \& A, 2001. 
LUCKESI, C. C. Avaliação da aprendizagem: componente do ato pedagógico. São Paulo: Cortez, 2011.

MORETTO, P. V. Avaliar com eficácia e eficiência. In: MORETTO, P. V. Prova: um momento privilegiado de estudo, não um acerto de contas. 9a ed. Rio de Janeiro: Lamparina, 2014, p. $115-151$.

SANTOS, E. R. dos. Análise da produção escrita em matemática: de estratégia de avaliação a estratégia de ensino. 2014. 156 f. Tese (Doutorado em Ensino de Ciências e Educação Matemática) - Centro de Ciências Exatas, Universidade Estadual de Londrina, Londrina, 2014.

SMITH, M. S. et al. Student-constructed representations: Vehicles for helping teachers understand students' mathematical thinking. In: BLUME, Glendon; HEID, Mary Kathleen; SMITH, Margaret Schwan. 2001 Yearbook of the Pennsylvania council of teachers of mathematics: The role of representation in the teaching and learning of mathematics, State College, PA: The Council of Teachers of mathematics, p. 65-69, 2001.

TREVISAN, A. L.; MENDES, M. T. A Prova Escrita como Instrumento de Avaliação em Aulas de Matemática. Educação Matemática em Revista, v. 45, p. 48-55, 2015. Disponível em: <https://goo.gl/1DY9nv> Acesso em: 20 out. 2017.

PEREGO, F. O que a produção escrita pode revelar? Uma análise de questões de matemática. 2006. 128f. Dissertação de Mestrado (Programa de Pós-Graduação em Ensino de Ciências e Educação Matemática) Universidade Estadual de Londrina, Londrina. 2006.

PEREIRA JUNIOR, A. Enunciados de Itens de provas de Matemática: um estudo na perspectiva da Educação Matemática Realística. 2014. 68f. Dissertação de Mestrado (Programa de Pós-Graduação em Ensino de Ciências e Educação Matemática) Universidade Estadual de Londrina, Londrina, 2014.

VAN DEN HEUVEL - PANHUIZEN, M. Assessment and realistic mathematics education. Utrecht: $C D-\beta$ Press/Freudenthal Institute, Utrecht University, 1996. Disponível em: <https://goo.gl/nP3VXj> Acesso em: 20 nov. 2017. 
Recebido: 2018-05-30

Aprovado: 2019-03-06

DOI: $10.3895 /$ rbect.v12n2.8341

Como citar: PEREIRA, F. F.; DONEZE, I. S.; MENDES, M. T.; DALTO, J. O. Tarefas matemáticas para uma prova escrita: uma discussão a partir da produção escrita de alunos. Revista Brasileira de Ensino de Ciência e Tecnologia, v. 12, n. 2, 2019. Disponível em: <https://periodicos.utfpr.edu.br/rbect/article/view/8341>. Acesso em: $\mathrm{xxx}$.

Correspondência: Marcele Tavares Mendes - marceletavares1982@gmail.com Direito autoral: Este artigo está licenciado sob os termos da Licença Creative Commons-Atribuição 4.0 Internacional.

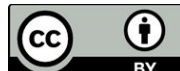

